\title{
The education system, demography and unintended consequences
}

\section{GERALDINE MCDONALD}

\section{Abstract}

A major feature of the past year has been public discussion about education. The solution to problems in the outcomes of schooling have almost invariably been seen in the processes of teaching and learning. There has been little discussion of the education system itself. Examples are provided of effects which are education system related but independent of teaching.

\section{Introduction}

The PISA study reveals that at age 15 there is a "long tail" comprising a high proportion of young people whose educational attainment falls well below the median. Average attainment scores are strong relative to other countries but far too many young people, especially Māori and Pacific Island peoples, are left behind with adverse human and economic circumstances. (Boven, 2010, p. 2)

7 This information came from the results of an international test called the Programme for International Student Assessment 1 (PISA) conducted by the Organisation for Economic Cooperation and Development, and news of the tail has been reported many times together with a determination to fix it. Stimulated by the Government's introduction of national standards and the attempt to increase class size, a major feature of the past year has been public discussion of education. The long tail has caused anxiety, and there is doubt that the traditional link between educational qualifications and employment is as strong as it once was.

The solutions suggested for poor academic performance have almost invariably related to teaching and learning, often 
recommending practices which follow a tutoring model such as feedback and feed forward. The debate on how to improve education has rarely extended beyond stating the need for single factors such as "improved teacher quality" and "standards". Apart from a formula such as, "the education system is failing boys (or Māori)", the education system itself has been overlooked as a factor in the outcomes of education and in understanding it as evidence for educational outcomes. Yet a change in the education system seldom has only one effect.

\section{Education systems}

There are system issues which go beyond policies determining the movement of cohorts from class to class and although education systems share features common to all on other characteristics, they may differ.

The mysterious rise in IQ has led to what IQ tests really measure. IQ tests arose because of the problems of universal education. It was believed at the time that standardised tests tapped hereditary forces and maturation and hence the correct way of assessing ability was to use chronological age as the standard. Cahan and Cohen (1989) published the results of a study based on 12,000 pupils in the Hebrew language school system of Jerusalem. The authors wanted to find out whether IQ test items were more strongly influenced by age than by schooling. They used a technique called a regression discontinuity design in which a year of schooling was measured by comparing the performance of pupils on both sides of the cut-off point for promotion to the next class. There would be a difference in schooling of one year between them. The authors found that although there was variation according to type of test item, schooling contributed more than age on all test items and for some items schooling contributed twice as much as age.

Martin, Mullis and Foy (2011), the IEA PIRLS team, wanted to use the Cahan and Cohen regression continuity technique with the PIRLS 2006 data. However, the technique needs scores from pupils in two adjacent classes and although Norway and Iceland entered a Grade 5 class, other countries supplied information for Grade 4 only. 
In their analysis of the characteristics of the education systems which were part of the PIRLS testing, the authors state that it is difficult to determine a straightforward relationship between agewithin-grade and achievement across countries and that older students do not necessarily perform better. There was great variation in the education systems in the PIRLS study regarding age of entry to school, method of entry, and whether, once in school, pupils move automatically from grade to grade or whether some pupils are delayed. From the education systems which took part in PIRLS 2006 the authors identified two major ways of organising an education system. In the first, children enter on a fixed date and then progress automatically year by year. Three systems of this type were identified: Iceland, Norway and England. Three other systems were identified in which "the combined effect of entry and promotion and retention practices is that of producing a predominant age cohort with uniform reading achievement, together with an older group with lower achievement and a (smaller) younger group with higher achievement" (Martin et al., 2011, p. 25). The countries selected to represent this pattern were Germany, the United States and Austria. New Zealand has the characteristics of this second group. As age increases month by month within the year group systems of this second type produce a flat line of achievement by Grade 4. Marion de Lemos (1989), working in Australia on standardising tests, had come to a similar conclusion for the systems in her country. In the education systems in which pupils proceed automatically there is an achievement slope from youngest to oldest, a pattern familiar from studies concerned with the effect of birthdates.

I became very interested in education systems and why they differed. I had access to scores from TIMSS but there were no general statistics for England which made any conclusions somewhat tentative. However, or New Zealand I demonstrated the flat line described by Martin et al. (2011) for systems that allow retention (McDonald, 2001) and I showed the pattern of retention and acceleration according to month at age 10 . 


\section{Unintended consequences}

Between 1932 and 1935 5-year-olds were excluded from New Zealand schools as a cost-cutting measure. As a consequence, some children entered at 6 years, spent one or part of a year in the Primers and then proceeded to the Standards. Others also entered at 6 but spent two years or more in the Primers. The annual reports to Parliament show that the median ages of both girls and boys began to rise. Children were becoming older for class level. By 1936 the median age in Standard IV was 11.5 months for boys and 11.2 for girls. By 1938 the median ages at Standard IV had increased to 11.8 and 11.5 and there they remained until 1941 when median ages at Standard IV fell to 11.6 and 11.4 , the point where they had been 10 years earlier. There had been a substantial increase in the number of children delayed in their progress through school. When our Treasury discussed the policy of increasing class size, a policy which was subsequently abandoned, were they aware of the number of children whose progress would have been delayed as class size expanded?

It seemed to me that education systems were poorly understood and that this led to unrealistic assumptions about educational causes and effects. Teachers do not control education systems. When teachers became organised, they were able to present the case for smaller classes but as teachers they cannot determine the shape of the system, or the regulations controlling the progress of children up the ladder of schooling. Student flows, for example, are determined by conditions such as population pressure, regulations on class size, ratio of teachers to pupils, and room in the next class (Frederiksen, 1983). Teachers work within this system. On the other hand, the system may work against the achievement gains which can be attributed to teaching. Education systems are not simple, and the remainder of this account consists of descriptions of aspects of education which are not the consequence of teaching; rather, they are features related in varying ways to age in grade (class level) patterns. When education systems are stable it probably matters little if no-one knows how the system operates but once changes are introduced it is desirable to have such knowledge and know whether there might be unintended consequences. 


\section{The birthdate as a system effect}

There is a longstanding belief that the season of the year in which one is born, or the month of birth, affects intelligence and ability to learn. There have been numerous explanations for why groups of children born in particular months have lower average achievement scores than children with different birthdates. Although the problem of the "summer born" has been associated particularly with the education system of England, the issue has been identified in a range of OECD countries (Bedard \& Dhuey, 2006) and the popularity of the topic can be seen in a recent review of research papers on the subject published since 1990 (Sykes, Bell, \& Rodeiro, 2009).

Tests of the intelligence of school children, which could be answered on paper, were developed in the 1920s by a team who had first developed tests for entrants to the United States army during the First World War. These self-administered tests spread rapidly to other countries including New Zealand. Season of birth effects had earlier been sought in physical capacity such as strength and growth. Intellectual effects had been restricted to matters such as establishing the birthdates of prominent men. The new tests were capable of testing large numbers of pupils and opened the way for the study of the relationship between date of birth and IQ. Several tests, including Otis tests, were used to supply scores.

Rudolph Pintner, a pioneer in the study of the effect of the seasons, was born in England in 1884 but moved to the United States where he eventually became a prominent academic at Teachers College Columbia University. He was interested in issues to do with disability, he developed standardised tests of intelligence and he was a leader in the study of the effect of seasons on intellect, believing that winter affected what he called "the germ plasm." He published a paper on the subject in 1931 (Pintner, 1931) and with a colleague continued to publish on month of birth and its relationship to the IQ and other factors such as temperament (Pintner \& Forlano, 1933). In their 1933 paper, the data consisted of 17,502 IQs obtained from 13 different tests. 
Pintner lived in the Northern Hemisphere. Realising that the seasons differed according to hemisphere he obtained IQs from Australia but these did not show clear-cut results. A.B. Fitt, Professor of Education at Auckland University College, gained access to scores from the Otis test which was standardised in New Zealand in 1936. He could not make winter fit his results and concluded that in the Southern Hemisphere autumn was the dangerous time because that was when fading light induced processes of hibernation which affected the quality of the germ plasm. Fitt used scores which were age normed. These did not take account of the class placement of the children who had gained the IQs. Because in New Zealand some children are kept behind for a further year in the beginning classes, generally on the grounds of immaturity, age groups have a different composition according to place in the year group. Fitt provides no information on the class composition of his seasonal samples but they would have had different distributions of age by class level. This would have distorted his matching of IQ and time of conception. Although they shared the same season of birth they were not all at the class levels for their age. Apart from Fitt's (1941) monograph on the topic of seasonal effects, there seems to have been little interest in the birthdate in New Zealand until very recently.

Before it was disbanded, the Qualifications and Curriculum Authority in the UK commissioned the National Foundation for Educational Research (NFER) in 2009 under the leadership of Caroline Sharp to collect information about relative age effects. The report was to be a "Thematic Probe" which explored the existence of international effects. As part of this enterprise, information was sought from various countries including New Zealand. Ian Schagen, on secondment from NFER and attached to the New Zealand Ministry of Education, analysed for New Zealand age, position in class, and scores for reading from PIRLS 2006 and scores for Mathematics and Science from the Trends in International Mathematics and Science Study (TIMSS, 2006) concluding that birth month had a significant effect on New Zealand children's reading and maths scores with the oldest performing best (Sharp, George, Sargent, O’Donnell, \& Heron, 2009). This information needs to be treated with considerable caution. 
Schagen did not seem to understand the New Zealand system of school entry and selective promotion. He claimed that children born in February were the youngest in the class and that February children performed poorly in Mathematics. This finding reveals not a function of relative age. The explanation for difference is more likely to lie in the extent to which an age group is complete or incomplete for the expected level. Schagen's frame of reference appears to be one which matches the English education system with children of one age all moving together. New Zealand does have a cut-off date for promotion. It varies from school to school and affects only some children.

Using the scores from PIRLS 2006 to unravel age distributions and reading achievement configurations, Martin et al. (2011) concluded that older children do not necessarily have higher achievement than younger children.

PIRLS and TIMSS sample by grade (class level) and not by age and a New Zealand class will be a mixture of older children whose progress has been delayed as well as those with the same birth date but a year younger:

It is fundamental to recognise that students' age-within-grade can be manipulated by policy decisions and, in particular, that policies on age of entry to school and policies on promotion/retention can influence not just the average age but also the age distribution within a grade. (Martin et al., 2011, p. 13)

In the first year of schooling in New Zealand children's ages and length of schooling coincide. In the second year children who will have been at school for at least 18 months as measured at mid-year are eligible for promotion out of the Junior School. However, principals may also establish a cut-off date earlier in the year, often in March or April, which establishes a group referred to variously as "mid-yearentrants", "possibles" or even "doubtfuls". The younger the child in the year group, the greater the chance of being retained (see McDonald, 2001, p. 384). The effect of this practice is to spread children of one age over three class levels and for there to be representatives of three ages in one class. 
The practice of classification was originally set out in regulations and selective promotion was strongly backed by articles in Education, the Department of Education's journal. In 1962 the Commission on Education in New Zealand endorsed the practice of delay. It was praised as a "flexible" policy. Unfortunately it was flexible at the expense of Māori and of boys. Retention was frequent but acceleration was rare. Following the introduction of Tomorrow's Schools, new legislation was drafted, and in the Education Act 1989 the regulations on classification were omitted. By the time I began to look for statistics which would show whether or not children were still being retained, the former age by grade tables had been removed from the education statistics and in 1994 replaced with what later came to be called Funding Year Levels. On entry to the intermediate level of schooling the funding year figures were reset to show the age-grade position at Year 7. The increased number of students made it appear that there was some process of holding back taking place at Intermediate and subsequently at Secondary level. The increase seemed far more likely to have emerged on exit from the Junior School but had not been recorded at the time.

In 2010 I asked people with knowledge of junior school practice whether children were judged as needing another year to mature and all confirmed that the process described in the old regulations still applied. New Zealand is not the only country to hold children back with the best intentions for the child and indeed it does no harm to most children but for those from poorer families it increases the likelihood that they will drop out of school when they reach leaving age and that they will have had no opportunity to gain qualifications. Nobody expects this to happen but subsequent efforts to keep students in school may be thwarted by a process that occurs on exit from the beginning classes.

The practice of holding children back from entry to school is common in some parts of the US on the grounds that the children are young and "not ready". Shepard and Smith (1985, p. 29) have commented that "children are much more likely to be 'unready' for school because their parents have less education than because they are 'young'”. 
Academic redshirting may also affect the relationship of age to level. Redshirting has long been practised in the US and more recently in Australia and New Zealand. The process applied originally to sports. Boys would delay entering formal sport to allow increase in growth and skill to improve their chances of selection. In academic redshirting those children, generally boys, who are amongst the youngest in the year group may be held back in kindergarten or the first year of school in order to be the oldest when they are promoted. Academic redshirting is intended to increase a boy's (it is usually a boy) chance of being a leader and top of the next class. There is no firm agreement whether the practice is helpful to a child but since it is confined largely to boys from middle class families it is unlikely to end up in early leaving.

The economists Dhuey and Lipscombe (2008) report that, on the assumption that high school leadership is a sign of good genetics or family background, it is likely to lead employers to offer positions with a good wage. However, they point out that high school leadership may arise simply because of a student's relative age determined by the school structure, the oldest in the year group being most likely to assume leadership. Probably some have been retained in the beginning classes to achieve this result.

\section{Ethnic and gender differences}

While practices within a single system are more uniform than they are across systems, there are variations in age by grade across schools in any one system. These may arise because of factors such as population pressure on school rolls, and parents' attitudes to time of entry, When it was announced that the proposed increase in class size in New Zealand was too small to make a difference, the judgement appears to have been related to group achievement. Yet, as the experience in the 1930s shows, individual children were likely to have been kept back to maintain larger class sizes.

In 1988 the process of repeating a class affected 6- to 7-year-old children according to ethnicity and gender. Pākehā girls had the greatest chance of being promoted out of the Junior School, Pākehā boys the next greatest chance, Māori girls were next, and Māori boys 
came last (McDonald, 1988). Although the Ministry of Education does not publish the relationship between chronological age and year level, it does publish statistics relating to gender and ethnicity and the number in each category attending school each year. Education Counts records figures for Pākehā girls, Pākehā boys, Māori girls and Māori boys, and other smaller ethnic categories.

The earliest record of attendance by ethnicity appeared in Funding Year 1 in July 2004. I then looked at the figures for Pākehā girls and boys and Māori girls and boys at 1 July 2010 to see how many of the original ethnic cohorts were still at school. See Table 1 for the results.

Table 1. Retention in school by gender and ethnicity

\begin{tabular}{cccc}
\hline Pākehā girls & Pākehā boys & Māori girls & Māori boys \\
\hline $87 \%$ & $79 \%$ & $50 \%$ & $43 \%$ \\
\hline
\end{tabular}

Calculations based on figures from Education Counts.

The order of retention by gender and ethnicity in secondary school mirrors the order found in 1988 for exit from the junior school. The Pasifika group had stayed in school in proportions almost equal to the Pākehā group and no Asian pupils had dropped out.

\section{Economists and birthdate}

A group of economists (Crawford, Dearden, \& Meghir, 2010) collected information from every local body in England regarding method and age of entry to school. The authors followed the fate of cohorts up to their involvement in the workforce concluding that the fiscal impact of date of birth can be traced through to employment. The authors stressed the importance of the time when children were judged. They suggest that young children should not be tested at times related to the school year such as halfway through and at the end of the school year. Reports to parents would be much fairer, they say, if children were tested at the same age to offset the birth date effect. This is already done in the Six-Year-Net used to determine whether or not New Zealand children would be helped by Reading Recovery.

There is insufficient evidence of a birth date effect in New Zealand to adopt any of the corrections that have been suggested, such as the 
teacher calling the roll in date and not in alphabetical order to remind everyone of the birth date effect, or that age adjusted scores should be used. Nevertheless, if children are to be tested for national standards in their first year at school and before any promotion decisions, thought could be given to testing children not in relation to the school year, but according to a standard age. While this is the fairest way to judge children, it may not be the best way to judge schools.

\section{Change in "mental ability"}

The IQ score begins as a raw score or number of correct answers and this is compared with the average score of others of the same age in years and months. The result is then converted to an IQ which is generally a position on the error curve with a mean of 100 and a Standard Deviation of 15 . For any given raw score, the younger the individual, the higher the IQ. Now recall also that Cahan and Cohen (1989) had established that class level contributed more to success on IQ items than age. Also consider the education system itself. The New Zealand system began with standards to be reached before children were promoted to the next class and for some time the result was that large numbers of children remained in the early classes. This position appears to have been universal and many authorities in the United States set up investigations to determine the cause (Volkmor \& Noble, 1914). There was not a great deal of change in the relation between age and class level until the late 1930s when social promotion began to gain favour, secondary education was expanding, and education systems lost their collections of children as young as 10 in the Primer classes (McDonald, 2010). The last New Zealand standard, Proficiency, which gave pupils access to free secondary education, was eliminated in 1936. The overall result was that age fell steadily at class level.

The scores from the Otis and other intelligence tests were increasingly accepted as an accurate measure of intelligence. United States soldiers in World War II tested with the original Army Alpha Test were found to have performed better than their World War I counterparts (Tuddenham, 1948). Another example of score rise occurred in Scotland where a Moray House Test given originally to a 
complete cohort of 11-year-olds in Scotland in 1932 was given again to 70,000 11-year-olds in 1947. There had been a fear that because the lower orders had large families and the middle classes did not, the national intelligence would have fallen. The national IQ had in fact risen by 2 points (Scottish Council for Research in Education, 1949).

In 1936, Redmond and Davies (1940) collected the figures for a New Zealand standardisation of an Otis Intermediate test of Mental Ability for pupils in primary and lower secondary school. In 1968, the test was re-standardised (Elley, 1969). A comparison of the results showed substantial gains. Elley (1969) reported that New Zealand children had gained a year of mental age. He suggested that "it it is certainly difficult to attribute the gain shown in the study to hereditary factors” (p. 153). He explained that the gain over the years amounted to half a standard deviation which translates into 7 points of Otis IQ. Although Elley attributes possible causes in a tentative fashion, he clearly favours educational agencies of varying kinds. There is no suggestion in his report that the large gain might have anything to do with the demographic structure of the education system and particularly the lowering of age for class level and the interaction between age in grade and the calculation of the IQ.

There are at least two ways in which age by grade (class level) figures could help to pinpoint an explanation for the rise. In the 32 years the median ages of boys and girls had steadily fallen at class level. Children had become younger and the collection of 10-year-olds in classes below Standard 3 had all disappeared by 1968. The 10-yearold cohort in 1968 was a year younger for schooling level than its counterpart in 1936 and so would have gained 7 points of IQ by virtue of being one class level higher.

This is only one way of demonstrating that the rise in IQ was the consequence of alteration in the relationship between age and class level. The distribution of 10-year-olds across classes in 1936 included 10 -year-olds below Standard 3. The percentage of 10 -year-olds at each class level were calculated as a basis for a comparison of results from the two years. The proportions were then assigned a class norm (Redmond \& Davies, 1940, p. 113). Below Standard 3, 10-year-olds had no class norms and they received a score of zero. The comparison 
of scores for each of the years 1936 and 1968 showed a difference of 6.4 points of IQ. The difference between this figure and the 7 points of IQ reported by Elley could be attributed to test sophistication but much of the mental gain was due to the upward movement of children in the beginning classes.

\section{A dilemma}

As long ago as 1958, Colgan, a high school principal, pointed out that the slow rate of progress of pupils through primary school meant that boys often did not reach secondary school before they became eligible to leave and promptly did so. He pinpointed particularly boys with birthdays from March to mid-year as the students most likely to drop out. These are the ones most likely to have been retained. Getting everyone to stay in secondary school remains a problem which we share with other countries.

However, the delay of some of the youngest on exit from the junior classes appears to avoid creating a birth date effect, the condition which troubles English pupils. At the same time the practice increases the likelihood of early leaving by those kept back. Holding back takes place in the second year of schooling and certainly there is no intention of doing harm to any pupil. Yet it is the Māori boys who are most likely to repeat a year. Efforts to keep Māori boys from dropping out of school are at risk of being forestalled by their delay in progress up the ladder of schooling. There is no easy answer but there are possibilities. Accepting that some pupils do need extra tuition, especially regarding literacy, this should be supplied at all levels where pupils need help and not be concentrated in the beginning years. Some education systems follow this pattern and indeed help of this kind exists in NZ. The issue is not about whether teaching would help, but at what point or points in the system help should be available.

Cohorts of pupils should be tracked throughout their schooling to detect any patterns of delay which need to be addressed. For many years it was possible to carry out such tracking but in 1994 the age by grade information was removed. Even with re-setting at Intermediate and Secondary levels it is now impossible to use the published 
statistics to follow any delay in the early years of schooling, its size and exactly when it occurs.

\section{General changes}

As Martin et al. have demonstrated, in all countries with universal provision of education the system takes a similar but not identical form. This common system used to be held together by "rulegoverned processes, centralised legal frameworks and shared assumptions" as underpinning the traditional forms of universal systems of education (Ozga, 2009, p. 149). The use of computers has greatly increased the ability to collect, analyse and store data. In her comments on the English education system today, Ozga argues that "the massive growth of data has unbalanced the relations of governing and created highly centralised system steering” (p.149). This is exactly what is happening in New Zealand too.

This article has tried to show that the education system has a life of its own. It has unintended consequences, produces its own effects on children's achievements and it can counter gains from effective teaching. Schools can make their own decisions on aspects of promotion/retention. Will league tables based on National Standards encourage any schools to hold more pupils back?

And what about the long tail? As Clark (2012) has pointed out, within-school solutions are likely to be ineffective in reducing an inequality which arises outside the education system.

\section{Conclusion}

I have outlined aspects of the New Zealand education system which are not the result of teaching and, particularly, those features which may have unintended consequences or which appear to be poorly understood. The analysis by the PIRLS team provides a new way of looking at education systems. One kind of system admits children on a fixed date and moves them up automatically year by year and another, like our own, allows retention and acceleration in the early years and which does not produce a birthdate slope. Knowledge about changes over time in the patterns of age by grade together with how IQ tests 
are scored provide a key to the explanation for rising scores. Systems are interconnected and the selective promotion of our system is connected to whether students stay in school or drop out. It would be desirable to follow the flow of students through school but for that to happen, age by grade tables would need to be reinstated.

\section{References}

Bedard, P. K., \& Dhuey, E. (2006). The persistence of early childhood maturity: International evidence of long-run age effects. The Quarterly Journal of Economics 121(4), 1437-1472.

Boven, R. (2010). Education and skills. Paper prepared for COMET (City of Manukau Educational Trust) annual report 09/10. Retrieved from http//www.nzinstitute.org.

Cahan, S., \& Cohen, N. (1989). Age versus schooling effects on intelligence development. Child Development 60, 1239-1249.

Clark, J. (2012, June 7). Achievement inequality begins outside the education system. Dominion Post, p. B5.

Colgan, L. J. F. (1958). Age of entry to post-primary school. PPTA Journal, November, 14-16.

Crawford, C., Dearden, L., \& Meghir, C. (2010). When you are born matters: The fiscal impact of date of birth on educational outcomes in England. London: Institute for Fiscal Studies. IFS working paper W10/06.

De Lemos, M. (1989). Effects of relative age within grade: Implications for the use of age-norms for group tests of general ability. Bulletin of the International Test Commission, 28\&29, 21-44.

Dhuey, E., \& Lipscombe, S. (2008). What makes a leader? Relative age and high school leadership. Economics of Education Review, 27(2), 173-183.

Elley, W. B. (1969). Changes in mental ability in New Zealand school children. New Zealand Journal of Educational Studies, 4(2), 40-55.

Fitt, A. B. (1941). Seasonal influence on growth, function and inheritance. Wellington: New Zealand Council for Educational Research.

Frederiksen, B. J. (1983). Internal efficiency of school systems: A study in the use of pupil flow models for developing countries (Unpublished $\mathrm{PhD}$ thesis). Department of Educational Research, University of Lancaster, UK.

Martin, M. O., Mullis, I. V., \& Foy, P. (2011). Age distribution and reading achievement configurations among fourth-grade students in PIRLS 2006. IERI Monograph Series (Vol. 4). Massachusetts: Educational Testing Service and International Association for the Evaluation of Educational Achievement. Retrieved from www.ierinstitute.org/.../IERI_Monograph_ Volume_04_Chapter_1.pd... 
McDonald G. (1988). Promotion, retention and acceleration: How the school produces inequality in the face of good intentions. set: Research Information for Teachers 2, item 3.

McDonald, G. (2001). Comparing school systems to explain enduring birthdate effects. Compare, 31(3), 381-391.

McDonald, G. (2010). The Flynn effect and the demography of schooling. Teachers College Record, 112(7), 1851-1870.

Ozga, J. (2009). Governing education through data in England: From regulation to self-evaluation. Journal of Education Policy 24(2), 149-162.

Pintner, R. (1931). Intelligence and month of birth. Journal of Applied Psychology 15, 149-134.

Pintner, R., \& Forlano, G. (1933). The influence of month of birth on intelligence quotients. The Journal of Educational Psychology 24(8), 561-584.

Redmond, M., \& Davies, F. R. (1940). The standardization of two intelligence tests. Wellington: New Zealand Council for Educational Research.

Scottish Council for Research in Education. (1949). The trend of Scottish intelligence. London: University of London Press.

Sharp, C., George, N., Sargent, C., O’Donnell, S., \& Heron, M. (2009). International Thematic Probe: The influence of relative age on learner attainment and development. Slough: NFER.

Shepard, L. A., \& Smith, M. L. (1985). Boulder Valley kindergarten study: Retention practices and retention effects. Boulder, CO: Boulder Valley Public Schools.

Sykes, E. D., Bell, J. F., \& Rodeiro, C. V. (2009). Birthdate effects: A review of the literature from 1990-on. Cambridge: Cambridge Assessment. Retrieved from http://www.cambridgeassessment.org.uk/ca/digital/Assets/169664_ CambridgeLit_Review_Birthdate_d3.pdf

Tuddenham, R. D. (1948). Soldier intelligence in World Wars I and II. American Psychologist, 3, 54-56.

Volkmor, H., \& Noble, I. (1914). Retardation as indicated by one hundred city school reports. The Psychological Clinic, 8, 75-81.

\section{The author}

Dr Geraldine McDonald, now retired, has worked for the New Zealand Council for Educational Research and Victoria University of Wellington. She has long been interested in how education systems work and whether systems can supply answers to mysteries.

Email: geraldine.mcdonald@clear.net.nz 